\title{
Radiation protection in non-ionizing and ionizing body composition assessment procedures
}

\author{
Samantha Cornacchia ${ }^{1}$, Luciana La Tegola ${ }^{2}$, Arcangela Maldera ${ }^{1}$, Elena Pierpaoli ${ }^{3}$, Umberto Tupputi ${ }^{2}$, \\ Giovanni Ricatti ${ }^{2}$, Laura Eusebi ${ }^{4}$, Sergio Salerno ${ }^{5}$, Giuseppe Guglielmi ${ }^{2,6}$ \\ ${ }^{1}$ Medical Physics Unit, Dimiccoli Hospital Barletta, Barletta, ASL Barletta-Andria-Trani, Italy; ${ }^{2}$ Department of Clinical and Experimental Medicine, \\ Foggia University School of Medicine, Foggia, Italy; ${ }^{3}$ ASUR Marche, Medical Physics Unit, Ascoli Piceno, Italy; ${ }^{4}$ Radiologia Ospedale "Carlo \\ Urbani”, Jesi, Italy; ${ }^{5}$ Department of Radiology, University of Palermo, Palermo, Italy; “"Dimiccoli” Hospital, University Campus of Barletta, \\ Barletta, Italy
}

Correspondence to: Prof. Giuseppe Guglielmi. Department of Clinical and Experimental Medicine, Foggia University School of Medicine (http://www.unifg.it), Viale L. Pinto, 1 71121, Foggia, Italy; “Dimiccoli” Hospital, University Campus of Barletta, Barletta, Italy.

Email: giuseppe.guglielmi@unifg.it.

\begin{abstract}
Body composition assessment (BCA) represents a valid instrument to evaluate nutritional status through the quantification of lean and fat tissue, in healthy subjects and sick patients. According to the clinical indication, body composition (BC) can be assessed by different modalities. To better analyze radiation risks for patients involved, BCA procedures can be divided into two main groups: the first based on the use of ionizing radiation (IR), involving dual energy X-ray absorptiometry (DXA) and computed tomography (CT), and others based on non-ionizing radiation (NIR) [magnetic resonance imaging (MRI)]. Ultrasound (US) techniques using mechanical waves represent a separate group. The purpose of our study was to analyze publications about IR and NIR effects in order to make physicians aware about the risks for patients undergoing medical procedures to assess BCA providing to guide them towards choosing the most suitable method. To this end we reported the biological effects of IR and NIR and their associated risks, with a special regard to the excess risk of death from radio-induced cancer. Furthermore, we reported and compared doses obtained from different IR techniques, giving practical indications on the optimization process. We also summarized current recommendations and limits for techniques employing NIR and US. The authors conclude that IR imaging procedures carry relatively small individual risks that are usually justified by the medical need of patients, especially when the optimization principle is applied. As regards NIR imaging procedures, a few studies have been conducted on interactions between electromagnetic fields involved in MR exam and biological tissue. To date, no clear link exists between MRI or associated magnetic and pulsed radio frequency (RF) fields and subsequent health risks, whereas acute effects such as tissue burns and phosphenes are well-known; as regards the DNA damage and the capability of NIR to break chemical bonds, they are not yet robustly demonstrated. MRI is thus considered to be very safe for BCA as well US procedures.
\end{abstract}

Keywords: Body composition (BC); ionizing radiation (IR); non-ionizing radiation (NIR)

Submitted Dec 11, 2019. Accepted for publication Jun 08, 2020.

doi: 10.21037/qims-19-1035

View this article at: http://dx.doi.org/10.21037/qims-19-1035 


\section{Introduction}

Body composition (BC) is defined by Wang et al. (1) as the branch of biology that deals with the in vivo quantification of human body components. Body composition assessment (BCA) allows us to evaluate the health status in terms of nutritional status and to evaluate the efficacy of primary and secondary preventive nutritional strategies. It can be used for many clinical purposes: it's useful for assessing cachexia (2), often related to other serious disease (e.g., cancer) (3), and sarcopenia, a condition of increasing interest to the scientific community for its multiple clinical and socio-economic implications. BC can also estimate metabolic risk. It is well known that an excessive quantity of adipose tissue (AT) is related to increase morbidity and mortality (4). Metabolic risk, for instance, strongly depends on fat distribution: central obesity and ectopic fat accumulation are important metabolic risk factors $(5,6)$. Other features, such as waist circumference and waist-to-hip ratio are also strongly associated with metabolic risk $(7,8)$. Cardiac risk (9), liver disease (10), type 2 diabetes $(11,12)$ and cancer $(13,14)$ are related linked to large amounts of visceral adipose tissue (VAT). AT contains approximately $80 \%$ fat; the rest is water, minerals and proteins (15). Body mass index (BMI) is the main parameter for estimating body fat, but it does not provide information on the local distribution in the body (16-18). BC assessment usually involves middle-old aged people for diagnosis of osteoporosis and sarcopenia but it is also performed on children. Indeed, many studies using BC measures have been published on child obesity $(19,20)$, on the association between the pulmonary function in children with cystic fibrosis (21) and on the prevalence of under- and overweight children with neurodisability (22).

Medical techniques for BC assessing provide precise information about the quantity (23), quality and distribution of AT and lean tissue (LT), some using ionizing radiation (IR), such as computed tomography (CT) and dual energy $\mathrm{X}$-ray absorptiometry (DXA) (24), others using nonionizing radiation (NIR), such as magnetic resonance imaging (MRI) (25) and Ultrasounds (US) (mechanical waves) (26). Radiation protection issue has to be taken into account especially in children and younger patient's irradiation. The risk of cancer for a 20 -year-old patient is doubled compared with a patient aged 40 and is $50 \%$ lower for a patient aged 60 (27). Moreover, children are more radiosensitive, 3 to 4 times more sensitive than adults (28).

The new European Directive 59/2013 (29) enforced the need to justify medical exposure to IR and confirmed the process of optimization by the use of diagnostic reference levels (DRL) and close collaboration with medical physicists. The Directive also requires that adequate information about the benefits and risks associated with the radiation dose must be provided for patients. Cornacchia et al. (30) have recently analyzed what information should be reported in radiological report according to art.58 (b) of Directive 59. Regarding NIR, the risks for the population and workers are respectively described in European Directives 519/1999 (31) and 35/2013 (32). In particular the Directive 35/2013 covers all known direct biophysical effects and indirect effects caused by electromagnetic fields (EMF), but it specifies that long-term effects are not yet well-confirmed by scientific communities.

The most important difference between IR and NIR is the radiation energy used to acquire information: IR carries enough energy to remove electrons from atoms (ionization process) and to leave atoms in an unstable state, while NIR is not able to do this. Risks associated with IR are well known and there are many publications related to this issue. On the contrary, NIR effects, in particular on how weak EMF (as used in MRI) could affect human health, are still under discussion (33).

Given the importance of BCA in routine clinical practice we analyzed the different techniques available for BCA and suggested some recommendations to reduce patient's health risks associated with IR and NIR.

\section{Material and methods}

In order to better evaluate the radiation protection issues and risks on health, BCA techniques have been divided into two groups: one using NIR (MRI) and the other IR-based (DXA and CT). US belongs to a different group based on mechanical waves.

\section{NIR techniques}

\section{MRI}

MRI is mostly used in BCA to quantify the volume of AT (34) and muscles (35). High soft-tissue contrast in combination with absence of IR and increasing availability makes MRI the preferred method of choice and enables true volumetric three-dimensional imaging even in healthy volunteers and infants. The measurements of regional AT and LT, as well as diffuse fat infiltration in other organs, can be better obtained using Dixon imaging, where the 


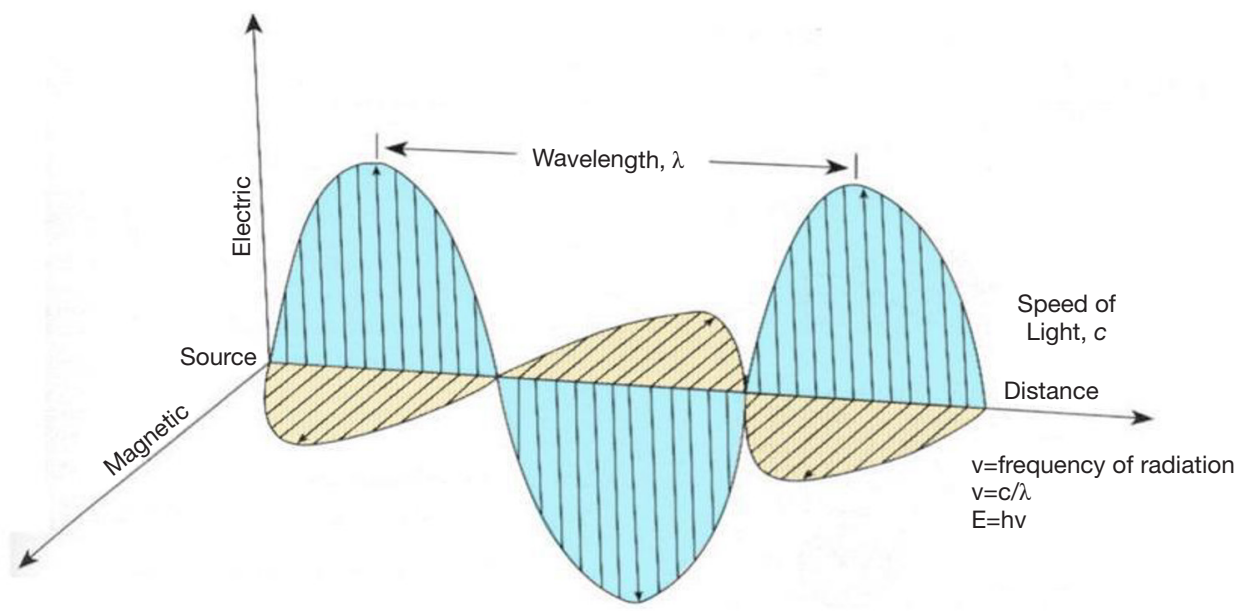

Figure 1 Schematic representation of the electromagnetic wave with its main physical features.

different magnetic resonance frequencies of protons in fat and water are used to separate the two signals into a water image and a fat image (36). Limitations of MRI include the high cost of acquiring the scan and the fact that it is not feasible for persons with claustrophobia (37). In recent years MRI has shown promising results in accurate measurement of BC (38). MRI is the more appropriate diagnostic method for muscle pathology progression (39); in particular, fat referenced MRI (40-44) provides a powerful tool for advanced $\mathrm{BC}$ assessment.

\section{NIR effects on biological tissue}

Radiations used in MRI procedures belonging to NIR not able to strip electrons from atoms; the supposed damage of NIR to DNA molecule and the capability of breaking chemical bonds have not yet been robustly demonstrated (45). Currently, there are some controversial studies reporting an increase in DNA damage following NIR exposure (46). Patients undergoing an MR investigation are exposed to a mixture of a static magnetic field (SMF), time-varying gradient magnetic fields (GMF) and pulsed radiofrequency fields (RF). The electromagnetic (EM) field represents a group of EM waves travelling with a certain frequency and energy, at the speed of light. In Figure 1 a schematic representation of the EM wave and its main physical features is shown.

\section{Exposure to $\mathrm{SMF}$-zero frequency}

The earth SMF is 50 micro Tesla $(\mu \mathrm{T})$ and varies from 30 to $70 \mu \mathrm{T}$, depending on the geographic location. During MR examinations, the patient is exposed constantly to a
$\operatorname{SMF}\left(\mathrm{B}_{0}\right)$, representing the maximum field intensity of the machine magnetic field, measured in Tesla units (typically $1.5,2$ or $3 \mathrm{~T}$ ). The effect of $\mathrm{B}_{\underline{0}}$ on water hydrogen protons in the human body is the spatial orientation of their magnetic moments along the direction of $\mathrm{B}_{0}$ (typically Zetaaxis, i.e., the patient's bed direction). Moreover, magnetic fields in the human body can move electric charges, for example blood cells moving in the field can reduce their velocity flowing through blood vessels (47). With regard to the clinical effects of SMF on tissue, it can be assumed that conventional magnetic resonance scanners operating up to $2 \mathrm{~T}$ are safe for patients. As far as long-term effects are concerned, a few epidemiological studies have been conducted on workers exposed to a moderate static field (several tens of $\mathrm{mT}$ ) with different endpoints including cancer incidence and chromosome aberration (48-51). For many reasons, ranging from methodological limitations to the very small numbers of people involved, these studies can be considered to be unresolved.

\section{Exposure to GMF-10-100 kHz frequency range or low frequency (LF)}

GMF are used to build an MR image and they are timedependent $(\mathrm{dB} / \mathrm{dt})$, overlapping to main field $\mathrm{B}_{0}$ in order to spatially select signals from different positions in the body. Gradients generate electric fields and currents inside the body that can interfere with the physiological electric fields and flows. Different exposure thresholds (depending on field frequency) can be established above which inducted internal fields can cause reversible effects on excitable cells (phosphenes) (52), nerves stimulation 
Table 1 Summary of non-ionizing radiation effects

\begin{tabular}{|c|c|c|c|}
\hline Magnetic field type & Physical interaction & Short-term effect & Long-term effect \\
\hline Static magnetic field & Electric charges motion & Nausea, vertigo, metallic taste & \\
\hline $\begin{array}{l}\text { Low frequency field } \\
\text { (gradients) }\end{array}$ & Induced electric fields and current & $\begin{array}{l}\text { Phosphenes, nerve stimulation, electric charge on the } \\
\text { skin }^{\S} \text {, cardiovascular-related, tissue burns }\end{array}$ & No evidence \\
\hline
\end{tabular}

§, reversible effects; ${ }^{\dagger}$, irreversible effects.

$(53,54)$ and electric charge effects on the skin. Irreversible effects such as cardiovascular-related or tissue burns can occur when thresholds are exceeded (55). Relating to longterm effects, actual evidence for cancer in adults from LF exposure does not exist; there are a considerable number of epidemiological studies $(56,57)$. After these studies, the International Agency for Research on Cancer (IARC) in 2002 classified LF fields as "possibly carcinogenic to humans" (category 2B) (58).

\section{Exposure to radio frequency (RF)- $\mathrm{MHz}$ frequency range or high frequency $(\mathrm{HF})$}

At the beginning of the MR exam, the scanner applies an $\mathrm{RF}$ field in the form of short pulses at specific intervals and supplies the useful energy to hydrogen nuclei for inducing the physical phenomena of resonance. Consequently, spin vectors that rotate with processional mote amplify this rotation. Effects of RF on patients are associated with tissue heating, quantified through the physical quantity specific absorbed rate (SAR), available on the MR scanner for each acquisition sequence. The SAR is the ratio between the energy transfer over time to a volume and the mass of that volume $($ Watt $/ \mathrm{kg})$. It is well known that above a certain level (thermal threshold) of RF exposure and temperature rise, heat-stroke and tissue damage (burns) can occur (59). Below the thermal threshold, many studies reported no conclusive evidence of adverse effects on health (60). At present, epidemiological data have not revealed possible health effects from chronic whole-body exposure and further researches are required. Finally, a consideration concerning patient safety has to be made: the interaction of $\mathrm{RF}$ with electronic implantable devices, such as pacemakers or defibrillators, can seriously compromise the proper operation of such devices. Table 1 summarizes the effects of the three fields described above.

\section{IR techniques}

\section{DXA}

DXA is the most popular diagnostic imaging method for quantifying fat, lean and total body bone mineral content; it works on the variation in the attenuation of two low-energy X-ray beams through tissues, due to their different composition. According to the World Health Organization (WHO), DXA is the gold standard for bone mineral density (BMD) measurements (61), but currently it has also been used to estimate total and regional body fat and lean. Given that it is fast, requiring 10 to 20 minutes to complete, has minimal radiation exposure $(<10$ micro Sieverts, $\mu \mathrm{Sv})$ and needs little technical skill for the operator (62), it is employed also for this scope. DXA estimates of $\mathrm{BC}$ are also affected by some limitations: differences among manufacturers in technology, models, and software employed (63) and physical limitations mainly due to body size (large patients don't fit in the scan area) (64).

\section{CT}

CT gives a three-dimensional high-resolution image volume of the complete or selected parts of the body and it uses the differences in $\mathrm{X}$-rays attenuations between lean soft tissue and AT to exploit the BCA (65). The standard CT protocol for BCA consists of a single abdominal slice through the level of L3-L4, the region of highest amount of abdominal fat. Moreover, CT can provide a contribution in cardio-metabolic risk stratification, analyzing pericardial fat, intrathoracic fat and epicardial fat $(66,67)$. In addition, CT can accurately determine fat in the liver. It is, however, significantly less accurate for liver fat $(<5 \%)$ which limits its use to diagnose low-grade steatosis. As far as microCT is concerned, it plays a significant role in small animals (mice), while there is still not enough evidence to suggest 


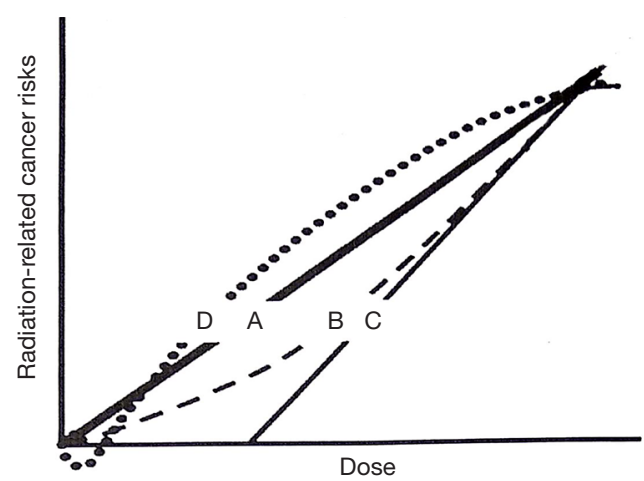

Figure 2 Schematic representation of different possible extrapolations of measured radiation risks down to very low doses. Curve A, linear (LNT model); curve B, linear quadratic; curve C, with threshold; curve D, hormetic. Adapted from (79). LNT, Linear Nothreshold Theory.

its routine use in humans. Finally, the term quantitative CT (QCT) indicates CT procedures where a standard calibration converts Hounsfield units (HU) of the CT image to $\mathrm{BMD}$ values.

\section{IR effects on biological tissue}

IR effects relate to the large energy loss of radiation within the body. The ratio between the energy absorbed by a biological tissue and the mass of volume where the energy is released, is defined absorbed dose $\mathrm{D}$ (measure unit Gray). The equivalent dose H (measure unit Sievert) takes into account the features of different radiations, whilst the effective dose E (measure unit Sievert) considers the different tissue radio-sensitivity. Effective dose is a radiation protection quantity calculated as the product of the equivalent dose and tissue-weighting factors; the International Commission on Radiation Protection (ICRP) recommends it to assess health risks related to low doses (68).

When IR interacts with water molecules in the body, it can create free radicals able to interact with DNA and cause strand breaks or base damage which is usually repaired; if not, a gene mutation or chromosome translocation can occur and lead to cancer, following a stochastic process, at any level of radiation exposure. Many studies have confirmed the evidence of radiation-induced cancer risk, from first reports of leukemia arising in radiation workers (69) until recent articles (70,71). Concerning radiation doses, studies on Japanese bomb survivors report an effective dose of $100 \mathrm{mSv}$, above which there is clear evidence of radiation-induced cancer risk (72). For doses below $100 \mathrm{mSv}$ (range, 10-100 $\mathrm{mSv}$ ), data provided by epidemiological studies are controversial: some researchers suggested an increased cancer risk (73-75), whereas others reported no evidence of carcinogenic effect from epidemiological data $(76,77)$. Current epidemiological studies do not offer the statistical power to detect an increased risk below $10 \mathrm{mSv}$ (28), though we cannot exclude it.

Linear No-threshold Theory (LNT) is the most accredited model to describe the relationship between cancer risk and low-doses (below $100 \mathrm{mSv}$ ): it predicts the direct proportionality between the two, extrapolating the excess of cancer risk from higher doses (78) (Figure 2, curve A). The central point of the LNT model is the assumption that the event leading to carcinogenesis is due to "onetrack action": a single electron track (produced during the ionization process) can cause one or more DNA double strand breaks; the track number is directly proportional to the dose and thus the cancer risk is proportional to the dose, with any dose. Many studies support the one-track assumption (80-83). The BEIR VII report, the ICRP and the United Nation Scientific Committee on the Effects of Atomic Radiation (UNSCEAR) (84) ratified the LNT model. The most notably controversy about this model comes from the French Academy of Sciences report. Furthermore, LNT does not represent the only model explaining the correlation between cancer and low doses. Data from the Life Span Study (85) reporting incidence of leukemia at intermediate doses, for example, correlate with a linear-quadratic curve (Figure 2, curve B); if the capability of immune system of removing pre-malignant and early tumor cells is considered, the curve trend is represented in Figure 2, curve C, providing the possibility of a practical threshold. Other investigators suggested that low dose radiation could have beneficial effects in reducing cancer (Figure 2, curve D), taking into account genomic instability, DNA damage prevention, apoptosis and bystander effects (86). IR can also interact directly with DNA, but this process is more likely for alfa and beta particles. Below 100 mGy of the acute organ absorbed dose, early or late tissue reactions can occur due to multiple damages to cells (79).

\section{US}

US represents a practical non-invasive technique to evaluate $\mathrm{BC}$ in a first step of assessment. It allows us to measure in real-time subcutaneous fat thickness and the cross - 
Table 2 Dose-area product and entrance skin dose for different DXA machines $(98,99)$

\begin{tabular}{lcc}
\hline Machine & DAP spine study $\left(\mathrm{mGy} \cdot \mathrm{cm}^{2}\right)$ & ESD $(\mu \mathrm{Gy})$ \\
\hline Lex X05 & 30 & - \\
Hologic 4500 & 36 & 200 \\
Lunar Prodigy & 10 & 37 \\
Lunar DPX & 5 & 10.25 \\
Norland XR 36 & 2 & $0.9-44.4$ \\
Hologic QDR 1000 & - & 60 \\
Hologic QDR 2000 & - & 138 \\
Lunar Expert & - & 895 \\
\hline
\end{tabular}

DXA, dual energy X-ray absorptiometry; DAP, dose-area product; ESD, entrance skin dose.

sectional areas of superficial muscles of the target structure, providing through predictions equations estimation of percent body fat and assessment of muscle $(87,88)$. The use of ultrasonography has traditionally had some advantages, such as the low cost, the speed of execution, the absence of IR, but it also has some limitations due to operator experience, absence of standardized procedure and sitespecific cut-off points, artifacts (89-91). Therefore, its use in the determination of $\mathrm{BC}$ is currently limited.

\section{US effects on biological tissue}

USs are mechanical waves propagating in a medium. When crossing biological tissue, the carried energy reduces with depth: tissue structures met along the beam path can reflect or absorb energy. We can divide interaction mechanisms of US into two categories: thermal and non-thermal. The thermal effect corresponds to temperature rising and depends on the physical quantity $\mathrm{I}_{\text {SPTA }}$ (spatial peak temporal average intensity), expressed in $\mathrm{mWatt} / \mathrm{cm}^{2}$ unit. Diagnostic levels of US can produce temperature rises that may be dangerous for sensitive organs and embryo/fetus (92). The non-thermic effect translates into a mechanical effect arisen from wave pressure. Cellular and subcellular structures exposed to US undergo torsion, rotational and translational forces due to the nonhomogeneity of acoustic energy. These forces can cause flows and vortices in fluids exposed (acoustic streaming), a phenomenon more relevant when investigating bladder, large vessels or amniotic liquid (93). Biological effects of a non-thermal origin have been reported in animals (94), but are not demonstrated in humans, except when a micro-bubble contrast agent was present (92).

\section{Results}

In this section, we reported radiation doses involved in different techniques based on IR and we suggested how to apply the optimization process to them. Furthermore, we described technical aspects and provided the main recommendations for NIR-based procedures, in order to reduce potential harms to patient.

\section{IR techniques}

As for BCA procedures, a general consideration is inherent for those patients with high BMI and thus with a greater thickness of the investigated area. Obese patient, indeed, typically will receive a greater effective dose in radiographic examinations with respect to normal weight patients $(95,96)$. Moreover, for patients undergoing CT, radiation dose reduction techniques cannot be used in patients with high BMI, because the noise level in images remains too high after the application of reduction dose algorithms (97).

\section{DXA}

Table 2 shows dose-area product (DAP) and entrance skin dose (ESD) measured with different DXA equipment, for spine study. DAP is the generally accepted standard for reference dose estimation in planar radiology: it is the incident air dose measured by a DAP meter multiplied by the field's area used for the study. ESD and DAP in each exam are correlated to organ dose. Mokhtari-Dizaji et al. (100) find a significant correlation between the dose at the scan center and thyroid and uterus surface doses, measured using a phantom and thermo-luminescent 
Table 3 Thyroid and uterus surface doses, calculated using a phantom with thermo-luminescent dosimeters; dose at scan centre was $6 \mu \mathrm{Gy}(101)$

\begin{tabular}{lc}
\hline Organ & Absorbed dose $(\mu \mathrm{Gy})$ \\
\hline Uterus & $1.21 \pm 0.33$ \\
Thyroid left lobe & $1.28 \pm 0.25$ \\
Thyroid right lobe & $1.18 \pm 0.17$ \\
\hline
\end{tabular}

Table 4 Summary of effective doses in typical DXA exams

\begin{tabular}{lc}
\hline Patient study & Effective dose $(\mu \mathrm{Sv})$ \\
\hline Women osteoporosis $(100,101)$ & $0.1-3.6^{\dagger}$ \\
Total body (102) & $0.1-75$ \\
Children exams (99) & $0.4-5.4$ \\
\hline${ }^{\dagger}$, depending on investigated anatomical district. DXA, dual \\
energy X-ray absorptiometry.
\end{tabular}

Table 5 Effective doses involved in different BCA procedures. Adapted from (27)

\begin{tabular}{lc}
\hline Technique & Effective dose $(\mathrm{mSv})$ \\
\hline DXA & $0.001-0.075$ \\
Radiograph & $0.3-0.7$ \\
CT & 3 \\
Periferical CT & $0.01-0.03$
\end{tabular}

BCA, body composition assessment; CT, computed tomography; DXA, dual energy X-ray absorptiometry.

dosimeter. Table 3 reports results and shows the dose at scan center $(6 \mu \mathrm{Gy})$. Table 4 resumes the effective doses in typical DXA exams. Although DXA doses are very low, Sheahan et al. identified three potential sources of overexposure: difference between beam area selected by operator and actual exposed area, incorrect fan-beam angle (the beam should fit exactly the detector area) and inadequate $\mathrm{X}$-ray tube filtration (98). Doses involved in DXA exams belong to a range $(<10 \mathrm{mSv})$ below which no epidemiological evidence exists for increased cancer risk. On the other hand, a small risk increase is always present when considering LNT model.

\section{CT}

Radiation doses involved in CT examination are orders of a magnitude greater than DXA doses. Depending on the CT protocol, indeed, radiation dose levels associated to examination ranges from 0.6 to $3 \mathrm{mSv}$ for a dedicated QCT. Moreover, it is well known that there is a large CT dose variability among different institutions (24). As an example, Damilakis et al. reported a typical dose level in an adult abdomen CT examination of about $8 \mathrm{mSv}$ and stressed the need to optimize protocols, preferring automatic exposure control (AEC) protocols to fixed-mAs protocols, reaching a dose sparing ranging from $15 \%$ to $60 \%$ (24). The need to reduce patient dose in CT-based techniques led us to explore the possibility of optimizing protocols without loss of density information. Mei et al. (103) demonstrated that many parameters characterizing bone structures such as $\mathrm{BMD}$, bone fraction and trabecular thickness are robust in low-dose protocols, allowing a dose reduction of about $90 \%$. Results reported in the article specify that these parameters are more stable if the dose decreases by reducing the number of projections acquired during a single rotation in CT scan instead of reducing mAs. However, this is not easy to obtain on a commercial scanner used in clinical setting modality. Museyko et al. (104) conducted a study on 26 cadavers: authors reported that lowering tube potential from 120 to 80 or $90 \mathrm{kV}$ may be considered as an important option to reduce radiation exposure. Moreover, they simulated a reduced mAs protocol (from 150 to 100 $\mathrm{mAs}$ ) finding that also tube load did not affect the results for bone integral volume or BMD. An interesting topic is the possibility to correlate the HU measured in specific bone segments to DXA measures in order to identify osteoporosis by using CT scans performed for other clinical indications $(105,106)$ and without an additional dose to patient being needed. Finally, Wu et al. (107) investigated the opportunity of dose reduction using iterative reconstruction. They reported a phantom study in which BMD has been evaluated for different combination of $\mathrm{mAs}$ and iterative reconstruction techniques. The same Authors demonstrated that, under different mAs and level of iterative reconstruction, the dose decreased significantly without affecting BMD accuracy. In Table 5 a comparison among doses involved in different BCA procedures is reported.

\section{Cancer risk}

The radiation dose from some CT (>10 mSv) falls within the range where a direct evidence for increase of cancer risk exists. In general, a $5 \%$ excess risk of death from cancer per $\mathrm{Sv}$ of effective dose is estimated $(108,109)$. Table 6 reports the excess risk of death for radio-induced cancer from a 
Table 6 Excess risk of death for radio-induced cancer from typical effective dose used in medical imaging examinations and comparison of medical imaging and background dose. Adapted from (75)

\begin{tabular}{lccc}
\hline Examination & Effective dose $(\mathrm{mSv})$ & Excess risk of death from cancer (\%) & $\begin{array}{c}\text { Time to accumulate comparable natural } \\
\text { background dose }\end{array}$ \\
\hline Quantitative CT & 3 & $<0.02$ & 1 year \\
DXA & 0.075 & $<0.001$ & 9 days \\
DXA low dose & 0.001 & $<0.00001$ & $<1$ day \\
\hline
\end{tabular}

$\S$, about $3 \mathrm{mSv} /$ year. CT, computed tomography; DXA, dual energy X-ray absorptiometry.

Table 7 ICNIRP limits of exposure to static magnetic fields. Adapted from (112)

\begin{tabular}{lc}
\hline Exposure characteristic & Magnetic flux density \\
\hline Occupational & $2 \mathrm{~T}$ \\
Exposure of head and trunk & $8 \mathrm{~T}$ \\
Exposure of limbs & $400 \mathrm{mT}$ \\
General public & \\
Exposure of any part of the body & \\
\hline ICNIRP, International Commission on Non-lonizing Radiation \\
Protection.
\end{tabular}

typical effective dose used in medical imaging examinations: the risk is calculated assuming a $5 \%$ excess risk of death from radiation-induced cancer per $\mathrm{Sv}$ of radiation and applying the LNT model.

Concerning the issue of risk communication to patients, a simple way to communicate radiological risk could be to compare doses from medical exposure with background doses (as in Table 6) or with the risk associated with normal daily activities. For example, doses between 0.1 and $1 \mathrm{mSv}$ relate to an increased risk of death from cancer equal to the risk associated with a 4,500-mile flight; doses between 1 and $10 \mathrm{mSv}$ with a 2,000-mile trip (28). Berrington De Gonzalez et al. (110) developed a tool to estimate the lifetime risk of cancer incidence from exposure to IR for doses below 1 Gy: it is an online calculator called Rad RAT, based on risk models of the National Academies of Sciences' BEIR VII Committee and US National Cancer Institute (111).

\section{MRI recommendations}

\section{Protection for SMF}

Protection against SMF effects previously described (nausea, vertigo, etc.) can be realized as indicated in DE 35/2013 and International Commission on Non-Ionizing Radiation Protection (ICNIRP) guidelines. Table 7 shows the limits of exposure of SMFs as indicated by ICNIRP (112) and transposed in DE 35/2013, for workers and the public.

For patients undergoing MRI procedures ICNIRP provides specific recommendations such as:

* To use the normal operating mode in routine MR examinations;

* To move patients slowly into the magnet bore to avoid the possibility of vertigo and nausea.

Moreover, the threshold for motion-induced vertigo has been estimated to be around $1 \mathrm{~T} / \mathrm{s}$ (for a time interval greater than $1 \mathrm{~s}$ ): the effects of induced electric fields and currents can be avoided undergoing this threshold. Finally, ICNIRP suggests limit exposition at $0.5 \mathrm{mT}$ (static field) in order to prevent interference with electronic medical devices implanted in patients.

\section{Protection for LF fields}

Interactions between body and external LF fields (gradients in MRI) must be checked, limiting exposure below the thresholds (with an additional preventive reduction factor) showing adverse effects; limits expressed in terms of induced internal electric field strength in $\mathrm{V} / \mathrm{m}$. Because of the complexity of measuring inducted internal electric field in the body, exposure limits outside the body can be defined (reference levels): remaining below reference levels in the air means that limits in the body are not exceeded. The ICNIRP Fact Sheet (55) represents a useful summary of LF effects and relative thresholds and reference levels, defined for workers and general public exposure. For patient undergoing MRI exams, MR factories give $\mathrm{V} / \mathrm{m}$ values related to gradients, but we should also consider the scan protocol in order to assess patient exposure. Frankel et al. confirm this need measuring GMF while varying some sequence parameters (113). 


\section{Protection for RF Fields}

The effect on biological tissue for RF relates to heat and they are proportional to the radiation power in the volume exposed (SAR). To prevent whole-body heat stress and excessive localized heating, the ICNIRP recommends limits for HF exposure, expressed in terms of SAR. Moreover, the MR scanner limits are in accordance with CENELEC (European Committee for Electrotechnical Standardization) regulations (114). In normal operating mode, keeping the whole-body SAR below $2 \mathrm{Watt} / \mathrm{kg}$ over any $6 \mathrm{~min}$ period allows average RF exposure not to exceed given limits (33). However, peak exposure can be higher $(100 \mathrm{~W} / \mathrm{kg}$ for a specific sequence) and RF field will vary depending on the sequence used (113).

\section{US recommendation}

The EFSUMB Federation suggests applying the ALARA (as low as reasonably achievable) principle also when using US imaging (92). US equipment screens are able to show a Thermal Index for guiding users regarding tissue heating and a Mechanical Index for likelihood and magnitude of non-thermal effects. Users should adjust machine controls in order to keep the two indexes as low as reasonably achievable, without loss of diagnostic information. If low values cannot be achieved, we can reduce examination times as much as possible.

\section{Discussion}

Among the BCA procedures, Cruz-Jentoft et al. (115) and Thomas et al. (34) recognized CT and MRI as the gold standard for the volumetric assessment of bone and body structures.

DXA is mainly used for BMD measurements (61), exposes patients to minimal radiation and has lower costs than CT and MRI. Because of this, DXA represents a valid alternative method to distinguish fat, bone mineral and LTs $(116,117)$. As for DXA, we noticed an evident variability among different equipment, due to technologies and clinical question to investigate and a strong correlation between patient dose and device and/or type of exam. Nevertheless, effective doses remain below $0.1 \mathrm{mSv}$.

As far as MRI procedures are concerned, only a few studies report the complexity of interactions of magnetic fields and effects on biological tissue. To date, we know that there is no evidence for adverse effects of exposure to SMFs used in MRI. As for RF fields, current consensus is that no clear link exists between MRI or associated magnetic and pulsed RF fields and subsequent health risks. The authors agree with Hill et al. about the conclusion reported in their study (45): "Although MRI imaging is generally considered to be safe compared with imaging technology using ionizing radiation, there is increased concern about the potential long-term bealth effects of exposure, especially with the push to bigher static fields along with stronger and faster switching fields. Although IARC (International Agency for Research on Cancer) did not find clear evidence that SMF are carcinogenic, the data are limited, underpowered, or suffer methodological weakness (118). Both $I A R C$ and the recent SCENIHR report suggest the need for a large, carefully designed epidemiology study". Finally, the authors agree with Frankel et al. (33) about the fact that interaction mechanism between EMF and biological tissue are not yet clear, especially regarding weak fields and nonthermal effects. Moreover, metric as SAR (for RF exposure) and induced electric field (for gradients exposure) may not be sufficient to study other effects (i.e., not heating or sensory effects or neuroexcitation).

US procedures are free-radiation safe methods to measure BCA.

As far as CT procedures are concerned, the main advantage in using them is that CT is the only modality along with MRI allowing a volumetric assessment of bone and body structures, whilst its main limitation is the IR exposure. Keeping the radiation dose as low as reasonably achievable and applying systematically the justification principle remains the most important strategy to reduce this potential risk. Recent literature investigated also the possibility to use CT scan performed for other clinical indications than BCA as an opportunistic screening method. Moreover, different technological solutions have been introduced to reduce dose in CT such as advanced AEC techniques working on tube current modulation more sensitive photon-counting detector that improve dose and image quality, and iterative reconstruction algorithm for routine clinical practice.

Patients involved in IR medical procedures could incur an excess of cancer risk over the time. The effective dose is the physical quantity recommended by ICRP to assess health risks linked to low doses. Because the effective dose refers to a standard size adult, we can use it only to assess a general level of radiation risk, not the individual risk involved in each diagnostic exposure. In any case, the individual effective dose and relative risk assessment required the advice of a medical physicist.

The LNT model remains the best and more conservative 
model correlating the radio-induced cancer risk to the dose. In general, the excess risk of death from cancer per Sievert is $5 \%$, whereas natural incidence of cancer mortality is around $25 \%$. In Table 1 we calculated the excess risk of death from cancer for different X-ray procedures, showing that the numbers of this risk are very low. Moreover, patients undergoing BCA procedures for Osteoporosis or Sarcopenia are middle-high aged with a consequent reduction of a long-term likelihood of radio-induced cancer.

An important issue is how to communicate risk to patient: in this paper we suggest the comparison between exam dose and time to receive the same dose from natural background.

We conclude sharing the recent position statement of American Association of Medical Physicists (119): "At the present time, epidemiological evidence supporting increased cancer incidence or mortality from radiation doses below $100 \mathrm{mSv}$ is inconclusive. As diagnostic imaging doses are typically much lower than $100 \mathrm{mSv}$, when such exposures are medically appropriate, the anticipated benefits to the patient are bighly likely to outweigh any small potential risks. Given the lack of scientific consensus about potential risks from low doses of radiation, predictions of hypothetical cancer incidence and mortality from the use of diagnostic imaging are highly speculative. The AAPM, and other radiation protection organizations, specifically discourages these predictions of hypothetical harm. Such predictions can lead to sensationalistic stories in the public media. This may lead some patients to fear or refuse safe and appropriate medical imaging, to the detriment of the patient. Medical physicists continuously strive to improve medical imaging by optimizing radiation doses while ensuring that the needed level of image quality is obtained, thereby contributing to the widely recognized benefits of medical imaging."

Despite demonstrated benefits, the scientific evidence that a "one track action" (i.e., a single track generated from the passage of a radiation) could cause irreversible DNA damage cannot be neglected, even when exposing to lowdose radiation.

\section{Acknowledgments}

Special thanks are given to Khatarine Gray and Christopher Williams for excellent English editing service.

Funding: None.

\section{Footnote}

Provenance and Peer Review: With the arrangement by the
Guest Editors and the editorial office, this article has been reviewed by external peers.

Conflicts of Interest: All authors have completed the ICMJE uniform disclosure form (available at http://dx.doi. org/10.21037/qims-19-1035). The special issue "Body Composition Imaging" was commissioned by the editorial office without any funding or sponsorship. GG served as the unpaid Guest Editor of the special issue and serves as an unpaid editorial board member of Quantitative Imaging in Medicine and Surgery. The authors have no other conflicts of interest to declare.

Open Access Statement: This is an Open Access article distributed in accordance with the Creative Commons Attribution-NonCommercial-NoDerivs 4.0 International License (CC BY-NC-ND 4.0), which permits the noncommercial replication and distribution of the article with the strict proviso that no changes or edits are made and the original work is properly cited (including links to both the formal publication through the relevant DOI and the license). See: https://creativecommons.org/licenses/by-nc-nd/4.0/.

\section{References}

1. Wang ZM, Pierson RN Jr, Heymsfield SB. The five-level model: a new approach to organizing body-composition research. Am J Clin Nutr 1992;56:19-28.

2. Fearon K, Strasser F, Anker SD, Bosaeus I, Bruera E, Fainsinger RL, Jatoi A, Loprinzi C, MacDonald N, Mantovani G, Davis M, Muscaritoli M, Ottery F, Radbruch L, Ravasco P, Walsh D, Wilcock A, Kaasa S, Baracos VE. Definition and classification of cancer cachexia: an international consensus. Lancet Oncol 2011;12:489-95.

3. Morley JE, Thomas DR, Wilson MM. Cachexia: pathophysiology and clinical relevance. Am J Clin Nutr 2006;83:735-43.

4. Borga M, West J, Bell JD, Harvey NC, Romu T, Heymsfield SB, Dahlqvist Leinhard O. Advanced body composition assessment: from body mass index to body composition profiling. J Investig Med 2018;66:1-9.

5. Britton KA, Fox CS. Ectopic fat depots and cardiovascular disease. Circulation 2011;124:e837-41.

6. Liu J, Fox CS, Hickson DA, May WD, Hairston KG, Carr JJ, Taylor HA. Impact of Abdominal Visceral and Subcutaneous Adipose Tissue on Cardiometabolic Risk Factors: The Jackson Heart Study. J Clin Endocrinol Metab 2010;95:5419-26. 
7. Chan DC, Watts GF, Barrett PH, Burke V. Waist circumference, waist-to-hip ratio and body mass index as predictors of adipose tissue compartments in men. QJM 2003;96:441-7.

8. Hsu CH, Lin JD, Hsieh CH, Lau SC, Chiang WY, Chen YL, Pei D, Chang JB. Adiposity measurements in association with metabolic syndrome in older men have different clinical implications. Nutr Res 2014;34:219-25.

9. Neeland IJ, Ayers CR, Rohatgi AK, Turer AT, Berry JD, Das SR, Vega GL, Khera A, McGuire DK, Grundy SM, de Lemos JA. Associations of visceral and abdominal subcutaneous adipose tissue with markers of cardiac and metabolic risk in obese adults. Obesity 2013;21:E439-47.

10. van der Poorten D, Milner KL, Hui J, Hodge A, Trenell MI, Kench JG, London R, Peduto T, Chisholm DJ, George J. Visceral fat: a key mediator of steatohepatitis in metabolic liver disease. Hepatology 2008;48:449-57.

11. Iwasa M, Mifuji-Moroka R, Hara N, Ishidome M, Iwata K, Sugimoto R, Tanaka H, Fujita N, Kobayashi Y, Takei Y. Visceral fat volume predicts new-onset type 2 diabetes in patients with chronic hepatitis C. Diabetes Res Clin Pract 2011;94:468-70.

12. Kurioka S, Murakami Y, Nishiki M, Sohmiya M, Koshimura K, Kato Y. Relationship between visceral fat accumulation and anti-lipolytic action of insulin in patients with type 2 diabetes mellitus. Endocr J 2002;49:459-64.

13. Britton KA, Massaro JM, Murabito JM, Kreger BE, Hoffmann U, Fox CS. Body fat distribution, incident cardiovascular disease, cancer, and all-cause mortality. J Am Coll Cardiol 2013;62:921-5.

14. Doyle SL, Donohoe CL, Lysaght J, Reynolds JV. Visceral obesity, metabolic syndrome, insulin resistance and cancer. Proc Nutr Soc 2012;71:181-9.

15. ICRP, 1975. Report of the Task Group on Reference Man. ICRP Publication 23. Oxford: Pergamon Press, 1975.

16. Prentice AM, Jebb SA. Beyond body mass index. Obes Rev 2001;2:141-7.

17. Tomiyama AJ, Hunger JM, Nguyen-Cuu J, Wells C. Misclassification of cardiometabolic health when using body mass index categories in NHANES 2005-2012. Int J Obes (Lond) 2016;40:883-6.

18. Thomas EL, Frost G, Taylor-Robinson SD, Bell JD. Excess body fat in obese and normal-weight subjects. Nutr Res Rev 2012;25:150-61.

19. Chung S. Body composition analysis and references in children: clinical usefulness and limitations, Eur J Clin Nutr 2019;73:236-42.
20. Plaza-Florido A, Migueles JH, Mora-Gonzalez J, MolinaGarcia P, Rodriguez-Ayllon M, Cadenas-Sanchez C, Esteban-Cornejo I, Navarrete S, Lozano RM, Michels N, Sacha J, Ortega FB. The Role of Heart Rate on the Associations Between Body Composition and Heart Rate Variability in Children With Overweight/Obesity: The ActiveBrains Project. Front Physiol 2019;10:895.

21. Engelen MP, Schroder R, Van der Hoorn K, Deutz NE, Com G. Use of body mass index percentile to identify fatfree mass depletion in children with cystic fibrosis. Clin Nutr 2012;31:927-33.

22. Lip SZL, Chillingworth A, Wright CM. Prevalence of under and over weight in children with neurodisability, using body composition measures. Eur J Clin Nutr 2018;72:1451-54.

23. Guerri S, Mercatelli D, Aparisi Gómez M, Napoli A, Battista G, Guglielmi G, Bazzocchi P. Quantitative imaging techniques for the assessment of osteoporosis and sarcopenia. Quant Imaging Med Surg 2018;8:60-85.

24. Damilakis J, Adams JE, Guglielmi G, Link TM. Radiation exposure in X-ray-based imaging techniques used in osteoporosis. Eur Radiol 2010;20:2707-14.

25. Baum T, Cordes C, Dieckmeyer M, Ruschke S, Franz D, Hauner H, Kirschke JS, Karampinos DC. MR-based assessment of body fat distribution and characteristics. Eur J Radiol 2016;85:1512-8.

26. Bazzocchi A, Filonzi G, Ponti F, Albisinni U, Guglielmi G, Battista G. Ultrasound: Which role in body composition? Eur J Radiol 2016;85:1469-80.

27. Smith-Bindman R, Lipson J, Marcus R, Kim KP, Mahesh M, Gould R, Berrington de González A, Miglioretti DL. Radiation dose associated with common computed tomography examinations and the associated lifetime attributable risk of cancer. Arch Intern Med 2009;169:2078-86.

28. Verdun FR, Bochud F, Gundinchet F, Aroua A, Schnyder P, Meuli R. Radiation risk:what you should know to tell your patient. RadioGraphics 2008;28:1807-16.

29. European Commission. Council Directive 2013/59 Euratom of 5 December 2013 laying down basic safety standards for protection against the dangers arising from exposure to ionizing radiations, and repealing Directives 89/618/Euratom, 90/641/Euratom, 96/29/Euratom, 97/43/Euratom and 2003/122/Euratom.

30. Cornacchia S, Errico R, Balzano RF, Fusco V, Maldera A, Pierpaoli E, Ferrari C, Rubini G, Guglielmi G. Medical radiological procedures: which information 
would be chosen for the report? La Radiologia Medica 2019;124:783-93.

31. 1999/519/EC: Council Recommendation of 12 July 1999 on the limitation of exposure of the general public to electromagnetic fields (0 Hz to $300 \mathrm{GHz}$ ). Publications Office of the EU, 1999;L 199:59-70. Available online: https://op.europa.eu/en/publication-detail/-/ publication/9509b04f-1df0-4221-bfa2-c7af77975556/ language-en

32. Directive 2013/35/EU of the European Parliament and of the Council of 26 June 2013 on the minimum health and safety requirements regarding the exposure of workers to the risks arising from physical agents (electromagnetic fields) (20th individual Directive within the meaning of Article 16(1. of Directive 89/391/EEC) and repealing Directive 2004/40/EC.

33. Frankel J, Wilén J, Hansson Mild K. Assessing Exposures to Magnetic Resonance Imaging's Complex Mixture of Magnetic Fields for In Vivo, In Vitro, and Epidemiologic Studies of Health Effects for Staff and Patients. Front Public Health 2018;6:66.

34. Thomas EL, Fitzpatrick JA, Malik SJ, Taylor- Robinson SD, Bell JD. Whole body fat: content and distribution. Prog Nucl Magn Reson Spectrosc 2013;73:56-80.

35. Cruz-Jentoft AJ, Baeyens JP, Bauer JM, Boirie Y, Cederholm T, Landi F, Martin FC, Michel JP, Rolland Y, Schneider SM, Topinková E, Vandewoude M, Zamboni M; European Working Group on Sarcopenia in Older People. Sarcopenia: European consensus on definition and diagnosis: Report of the European Working Group on Sarcopenia in Older People. Age Ageing 2010;39:412-23.

36. Dixon W'T. Simple proton spectroscopic imaging. Radiology 1984;153:189-94.

37. Lemos T, Gallagher D. Current body composition measurement techniques. Curr Opin Endocrinol Diabetes Obes 2017;24:310-4.

38. Taicher GZ, Tinsley FC, Reiderman A, Heiman ML. Quantitative magnetic resonance (QMR) method for bone and whole-body-composition analysis. Anal Bioanal Chem 2003;377:990-1002.

39. Tegola L, Mattera M, Cornacchia S, Cheng X, Guglielmi G. Diagnostic imaging of two related chronic diseases: Sarcopenia and Osteoporosis. J Frailty Sarcopenia Falls 2018;3:138-47.

40. Dahlqvist Leinhard O, Johansson A, Rydell J, Smedby O, Nystrom F, Lundberg P, Borga M. Quantitative abdominal fat estimation using MRI. 8-11 Dec. 2008; Tampa, FL, USA, IEEE, 2008:2137-40.

41. Karlsson A, Rosander J, Romu T, Borga M, Dahlqvist Leinhard O. Automatic and quantitative assessment of regional muscle volume by multi-atlas segmentation using whole-body water-fat MRI. J Magn Reson Imaging 2015;41:1558-69.

42. Romu T, Dahlqvist Leinhard O, Forsgren M, Almer S, Dahlström N, Kechagias S, Borga M. Fat water classification of symmetrically sampled two-point dixon images using biased partial volume effects. Proceedings of the Annual Meeting of the International Society for Magnetic Resonance in Medicine (ISMRM 2011), 2011.

43. Borga M, Thomas EL, Romu T, Rosander J Fitzpatrick J, Dahlqvist Leinhard O, Bell JD. Validation of a fast method for quantification of intra-abdominal and subcutaneous adipose tissue for large-scale human studies. NMR Biomed 2015;28:1747-53.

44. West J, Dahlqvist Leinhard O, Romu T, Collins R, Garratt S, Bell JD, Thomas L. Feasibility of MR-based body composition analysis in large scale population studies. PLoS One 2016;11:e0163332.

45. Hill MA, O'Neill P, McKenna WG. Comments on potential health effects of MRI-induced DNA lesions: quality is more important to consider than quantity. Eur Heart J Cardiovasc Imaging 2016;17:1230-38.

46. Vijayalaxmi, Scarfi MR. International and national expert group evaluations: biological/health effects of radiofrequency fields. Int J Environ Res Public Health 2014;11:9376-408.

47. Tenforde TS, Magnetically induced electric fields and currents in the circulatory system. Prog Biophys Mol Biol 2005;87:279-88.

48. Rockette HE, Arena VC. Mortality studies of aluminum reduction plant workers: potroom and carbon department. J Occup Med 1983;25:549-57.

49. Spinelli JJ, Band PR, Svirchev LM, Gallagher RP. Mortality and cancer incidence in aluminum reduction plant workers. J Occup Med 1991;33:1150-5.

50. Rønneberg A, Andersen A. Mortality and cancer morbidity in workers from an aluminum smelter with prebaked carbon anodes. 2. Cancer morbidity. Occup Environ Med 1995;52:250-4.

51. Rønneberg A, Haldorsen R, Romundstad P, Andersen A. Occupational exposure and cancer incidence among workers from an aluminum smelter in western Norway. Scand J Work Environ Health 1999;25:207-14. 
52. Saunders RD, Jefferys JG. A neurobiological basis for ELF guidelines. Health Phys 2007;92:596-603.

53. Nyenhuis JA, Bourland JD, Kildishev AV, Schaefer DJ. Health effects and safety of intense gradient fields. In: Shellock FG. editor. Magnetic resonance procedures: Health effects and safety. Boca Raton: CRC Press LLC, 2000:31-54.

54. So PPM, Stuchly MA, Nyenhuis JA. Peripheral nerve stimulation by gradient switching fields in magnetic resonance imaging. IEEE Trans Biomed Eng 2004;51:1907-14.

55. International Commission on Non-Ionizing Radiation Protection. Guidelines for limiting exposure to timevarying electric and magnetic fields $(1 \mathrm{~Hz}$ to $100 \mathrm{kHz})$. Health Phys 2010;99:818-36. Erratum in: Health Phys. $2011 \mathrm{Jan} ; 100(1): 112$.

56. Greenland S, Sheppard AR, Kaune WT, Poole C, Kelsh MA. A pooled analysis of magnetic fields, wire codes, and childhood leukemia. Childhood Leukemia-EMF Study Group. Epidemiology 2000;11:624-34.

57. Ahlbom A, Day N, Feychting M, Roman E, Skinner J, Dockerty J, Linet M, McBride M, Michaelis J, Olsen JH, Tynes T, Verkasalo PK. A pooled analysis of magnetic fields and childhood leukaemia. Br J Cancer 2000;83:692-98.

58. IARC Working Group on the Evaluation of Carcinogenic Risks to Humans. Non-ionizing radiation, Part 1: static and extremely low-frequency (ELF) electric and magnetic fields. IARC Monogr Eval Carcinog Risks Hum 2002;80:1-395.

59. D'Andrea JA, Ziriax JM, Adair ER. Radio frequency electromagnetic fields: mild hyperthermia and safety standards. Prog Brain Res 2007;162:107-35.

60. International Commission on Non-Ionizing Radiation Protection. ICNIRP statement on the "Guidelines for limiting exposure to time-varying electric, magnetic, and electromagnetic fields (up to $300 \mathrm{GHz}$ )". Health Phys 2009;97:257-8.

61. Garg MK, Kharb S. Dual energy X-ray absorptiometry: Pitfalls in measurement and interpretation of bone mineral density. Indian J Endocrinol Metab 2013;17:203-10.

62. Shepherd JA, Ng BK, Sommer MJ, Heymsfield SB. Body composition by DXA. Bone 2017;104:101-5.

63. Wang Z, Deurenberg P, Wang W, Pietrobelli A, Baumgartner RN, Heymsfield SB. Hydration of fat-free body mass: new physiological modeling approach. Am J Physiol 1999;276:E995-E1003.
64. Kuriyan R. Body composition techniques. Indian J Med Res 2018;148:648-58.

65. Malietzis G, Aziz O, Bagnall NM, Johns N, Fearon KC, Jenkins JT. The role of body composition evaluation by computerized tomography in determining colorectal cancer treatment outcomes: a systematic review. Eur J Surg Oncol 2015;41:186-96.

66. Eastwood SV, Tillin T, Wright A, Heasman J, Willis J, Godsland IF, Forouhi N, Whincup P, Hughes AD, Chaturvedi N. Estimation of CT-derived abdominal visceral and subcutaneous adipose tissue depots from anthropometry in Europeans, South Asians and African Caribbeans. PLoS One 2013;8:e75085.

67. Wang H, Chen YE, Eitzman DT. Imaging body fat: techniques and cardiometabolic implications. Arterioscler Thromb Vasc Biol 2014;34:2217-23.

68. The 2007 Recommendations of the International Commission on Radiological Protection. ICRP publication 103. Ann ICRP 2007;37:1-332.

69. Upton AC. Evolving perspectives on the biology and mechanisms of carcinogenesis. Leuk Res 1986;10:727-34.

70. Duncan JR, Lieber MR, Adachi N, Wahl RL. Radiation Dose Does Matter: Mechanistic Insights into DNA Damage and Repair Support the Linear No-Threshold Model of Low-Dose Radiation Health Risks. J Nucl Med 2018;59:1014-6.

71. Pierce DA, Preston DL. Radiation-induced cancer risks at low doses among atomic bomb survivors. Radiat Res 2000;154:178-86.

72. Health risks from exposure to low levels of ionizing radiation: BEIR VII-Phase 2. US National Academy of Sciences, National Research Council, Committee to assess health risks from exposure to low levels of ionizing radiation. The National Academies Press, Washington, DC, 2006.

73. Preston DL, Ron E, Tokuoka S, Funamoto S, Nishi N, Soda M, Mabuchi K, Kodama K. Solid cancer incidence in atomic bomb survivors:1598-1998. Radiat Res 2007;168:1-64.

74. Cardis E, Vrijheid M, Blettner M, Gilbert E, Hakama M, Hill C, Howe G, Kaldor J, Muirhead CR, SchubauerBerigan M, Yoshimura T, Bermann F, Cowper G, Fix J, Hacker C, Heinmiller B, Marshall M, Thierry-Chef I, Utterback D, Ahn YO, Amoros E, Ashmore P, Auvinen A, Bae JM, Bernar J, Biau A, Combalot E, Deboodt P, Diez Sacristan A, Eklöf M, Engels H, Engholm G, Gulis G, Habib RR, Holan K, Hyvonen H, Kerekes A, Kurtinaitis J, 
Malker H, Martuzzi M, Mastauskas A, Monnet A, Moser M, Pearce MS, Richardson DB, Rodriguez-Artalejo F, Rogel A, Tardy H, Telle-Lamberton M, Turai I, Usel M, Veress K. The 15-Country Collaborative Study of Cancer Risk among Radiation Workers in the Nuclear Industry: estimates of radiation-related cancer risks. Radiat Res 2007;167:396-416.

75. Lin EC. Radiation Risk From Medical Imaging. Mayo Clin Proc 2010;85:1142-6.

76. Tubiana M, Aurengo A, Averback D, Bonnin D, LeGuen B, Masse R, de Vathaire F. Dose-effects Relationship and Estimation of Carcinogenic Effects of Low Doses of Ionizing Radiations. Académie nationale de médecine. Paris: Institut de France-Académie des Sciences, 2005.

77. Tubiana M, Feinendegen LE, Yang C, Kaminski JM. The linear no-threshold relationship is inconsistent with radiation biologic and experimental data. Radiology 2009;251:13-22.

78. Shah DJ, Sachs RK, Wilson DJ. Radiation-induced cancer: a modern view. Br J Radiol 2012;85:e1166-73.

79. Brenner DJ, Doll R, Goodhead DT, Hall EJ, Land CE, Little JB, Lubin JH, Preston DL, Preston RJ, Puskin JS, Ron E, Sachs RK, Samet JM, Setlow RB, Zaider M. Cancer risks attributable to low doses of ionizing radiation: assessing what we really know. Proc Natl Acad Sci U S A 2003;100:13761-6.

80. Mole RH. Childhood cancer after prenatal exposure to diagnostic X-ray examinations in Britain. Br J Cancer 1990;62:152-68.

81. Doll R, Wakeford R. Risk of childhood cancer from fetal irradiation. Br J Radiol 1997;70:130-9.

82. Grosswendt B. Basic aspects of photon transport through matter with respect to track structure formation. Radiat Environ Biophys 1999;38:147-61.

83. United Nations Scientific Committee on the Effects of Atomic Radiation. 2006 report, volume 1: effects of ionizing radiation. Annex A: epidemiological studies of radiation and cancer. New York: United Nations Publication , 2008.

84. Little MP, Wakeford R, Tawn EJ, Bouffler SD, Gonzalez AB. Risks associated with low doses and low dose rates of ionizing radiation: why linearity may be (almost) the best we can do. Radiology 2009;251:6-12.

85. Feinendegen LE. Evidence for beneficial low level radiation effects and radiation hormesis. Br J Radiol 2005;78:3-7.

86. Authors on behalf of ICRP, Stewart FA, Akleyev AV,
Hauer-Jensen M, Hendry JH, Kleiman NJ, Macvittie TJ, Aleman BM, Edgar AB, Mabuchi K, Muirhead CR, Shore RE, Wallace WH. ICRP publication 118: ICRP statement on tissue reactions and early and late effects of radiation in normal tissues and organs--threshold doses for tissue reactions in a radiation protection context. Ann ICRP 2012;41:1-322.

87. Buckinx F, Landi F, Cesari M, Fielding RA, Visser M, Engelke K, Maggi S, Dennison E, Al-Daghri NM, Allepaerts S, Bauer J, Bautmans I, Brandi ML, Bruyère $\mathrm{O}$, Cederholm T, Cerreta F, Cherubini A, Cooper C, CruzJentoft A, McCloskey E, Dawson-Hughes B, Kaufman JM, Laslop A, Petermans J, Reginster JY, Rizzoli R, Robinson S, Rolland Y, Rueda R, Vellas B, Kanis JA. Pitfalls in the measurement of muscle mass: a need for a reference standard. J Cachexia Sarcopenia Muscle 2018;9:269-78.

88. Thiebaud RS, Abe T, Loenneke JP, Fujita E, Akamine T. Body fat percentage assessment by ultrasound subcutaneous fat thickness measurements in middle-aged and older adults. Clin Nutr 2019;38:2659-67.

89. Borkan GA, Hults DE, Cardarelli J, Burrows BA. Comparison of ultrasound and skinfold measurements in assessment of subcutaneous and total fatness, Am J Phys Anthropol 1982;58:307-13.

90. Fanelli MT, Kuczmarski RJ. Ultrasound as an approach to assessing body-composition. Am J Clin Nutr 1984;39:703-9.

91. Armellini F, Zamboni M, Rigo L, Bergamo-Andreis IA, Robbi R, De MM, Bosello O. Sonography detection of small intra-abdominal fat variations. Int J Obes 1991;15:847-52.

92. Kollmann C, Jenderka KV, Moran CM, Draghi F, Jimenez Diaz JF, Sande R. EFSUMB Clinical Safety Statement for Diagnostic Ultrasound - (2019 revision) [published online ahead of print, 2019 Oct 8]. EFSUMB-Statement über die klinische Sicherheit der Ultraschalldiagnostik - (2019 Revision). Ultraschall Med 2019. [Epub ahead of print]. doi:10.1055/a-1010-6018.

93. Ter Haar G. Ultrasonic imaging: safety considerations. Interface focus 2011;1:686-97.

94. Ang ESBC Jr, Gluncic V, Duque A, Schafer ME, Rakic P. Prenatal exposure to ultrasound waves impacts neuronal migration in mice. PNAS 2006;103:12903-10.

95. Yanch JC, Behrman RH, Hendricks MJ, McCall JH. Increased radiation dose to overweight and obese patients from radiographic examinations. Radiology 
2009;252:128-39.

96. Ector J, Dragusin O, Adriaenssens B, Huybrechts W, Willems R, Ector H, Heidbüchel H. Obesity is a major determinant of radiation dose in patients undergoing pulmonary vein isolation for atrial fibrillation. J Am Coll Cardiol 2007;50:234-42.

97. Wang R, Schoepf UJ, Wu R, Reddy RP, Zhang C, Yu W, Liu Y, Zhang Z. Image quality and radiation dose of low dose coronary CT angiography in obese patients: sinogram affirmed iterative reconstruction versus filtered back projection. Eur J Radiol 2012;81:3141-5.

98. Sheahan NF, Dowling A, O'Reilly G, Malone JF. Commissioning and quality assurance protocol for dual energy X-ray absorptiometry (DEXA) systems. Radiat Prot Dosimetry 2005;117:288-90.

99. National Osteoporosis Society. A practical guide to bone densitometry in children. Camerton, Bath, UK: National Osteoporosis Society, 2004.

100.Mokhtari-Dizaji M, Sharafi AA, Larijani B, Mokhlesian N, Hasanzadeh H. Estimating the Absorbed Dose to Critical Organs During Dual X-ray Absorptiometry. Korean J Radiol 2008;9:102-10.

101.Lewis MK, Blake GM, Fogelman I. Patient dose in dual x-ray absorptiometry. Osteoporos Int 1994;4:11-5.

102.Bazzocchi A, Ponti F, Albisinni U, Battista G, Guglielmi G. DXA: Technical aspects and application. Eur J Radiol 2016;85:1481-92.

103. Mei K, Kopp FK, Bippus R, Köhler T, Schwaiger BJ, Gersing AS,Kirschke J S, Noël P B, Baum T, Rummeny EJ. Is multidetector CT-based bone mineral density and quantitative bone microstructure assessment at the spine still feasible using ultra-low tube current and sparse sampling? Eur Radiol 2017;27:5261-71.

104. Museyko O, Heinemann A, Krause M, Wulff B, Amling M, Püschel K, Glüer CC, Kalender W, Engelke K. A lowradiation exposure protocol for 3D QCT of the spine. Osteoporos Int 2014;25:983-92.

105.Hoel RJ, Ledonio CG, Takahashi T, Polly DW. Sacral bone mineral density (BMD) assessment using opportunistic CT scans. J Orthop Res 2017;35:160-6.

106. Pickhardt PJ, Lee LJ, Muñoz del Rio A, Lauder T, Bruce RJ, Summers RM, Pooler BD, Binkley N. Simultaneous screening for osteoporosis at CT colonography: Bone mineral density assessment using MDCT attenuation techniques compared with the DXA reference standard. J Bone Miner Res 2011;26:2194-203.

107.Wu Y, Jiang Y, Han X, Wang M, Gao J. Application of low-tube current with iterative model reconstruction on Philips Brilliance iCT Elite FHD in the accuracy of spinal QCT using a European spine phantom. Quant Imaging Med Surg 2018;8:32-8.

108. International Commission on Radiological Protection. 1990 Recommendations of the International Commission on Radiological Protection. Ann ICRP 1991;21:1-201.

109. National Council on Radiation Protection and Measurements. Limitation of exposure to ionizing radiation Bethesda. MD: National Council on Radiation Protection and Measurements, 1993.

110.Berrington de Gonzalez A, Iulian Apostoaei A, Veiga LH, Rajaraman P, Thomas BA, Owen Hoffman F, Gilbert E, Land C. RadRAT: a radiation risk assessment tool for lifetime cancer risk projection. J Radiol Prot 2012;32:205-22.

111.RadRat radiation risk assessment tool. Version 4.1.1 (September 2015) Available online: https:// radiationcalculators.cancer.gov/radrat/ [accessed 2019 Nov 14]

112.International commission On Non-ionizing Radiation Protection. ICNIRP guidelines on limits of exposure to static magnetic fields. Health Physics 2009;96:504-14.

113. Frankel J, Hansson Mild K, Wilén J. Assessment of MRI patient exposure for epidemiological studies. In Joint Meeting of the Bioelectromagnetics Society and the European Bioelectromagnetics Association (BioEM 2015). Asilomar, CA: The Bioelectromagnetics Society and the European Biolectromagnetics Association, 2015

114.CENELEC. Medical Electrical Equipment - Part 2-33: Particular Requirements for the Basic Safety and Essential Performance of Magnetic Resonance Equipment for Medical Diagnosis. Brussels: CENELEC, 2016.

115. Cruz-Jentoft AJ, Baeyens JP, Bauer JM, Boirie Y, Cederholm T, Landi F, Topinková E. Sarcopenia: European consensus on definition and diagnosis: report of the European Working Group on Sarcopenia in older people. United States, North America: Oxford University Press, 2010.

116. Ceniccola GD, Castro MG, Fraga Piovacari SM, Horie LM, Corrêa FG, Noronha Barrere AP, Oliveira Toledo D. Current technologies in body composition assessment: advantages and disadvantages. Nutrition 2019;62:25-31.

117.Levine JA, Abboud L, Barry M, Reed JE, Sheedy PF, Jensen MD. Measuring leg muscle and fat mass in humans: comparison of CT and dual-energy X-ray absorptiometry. 
J Appl Physiol 2000;88:452-6.

118.HPA. Static magnetic fields. Report of an independent Advisory Group on Non-Ionising Radiation. Chilton, UK: Health Protection Agency, 2008. ISBN 978-0-

Cite this article as: Cornacchia S, La Tegola L, Maldera A, Pierpaoli E, Tupputi U, Ricatti G, Eusebi L, Salerno S, Guglielmi G. Radiation protection in non-ionizing and ionizing body composition assessment procedures. Quant Imaging Med Surg 2020;10(8):1723-1738. doi: 10.21037/qims-19-1035
85951-616-7.

119. American Association of Physicists in Medicine. AAPM position statement on radiation risks from medical imaging procedures (2018). Policy Number PP 25-C, 10. 